\title{
Haemophilia: Its Types and Prevalence in Pakistan
}

\author{
Kiran Fatima*, Rabeea Irfan, Laraib Azmat \\ Department of Biosciences, Faculty of Life Sciences, Shaheed Zulfikar Ali Bhutto Institute of Sciences \& Technology \\ (SZABIST), Karachi, Pakistan
}

ABSTRACT

Background: Haemophilia; classified by the inefficacy of blood to clot appropriately, is a genetic bleeding disorder. As a developing country, Pakistan has limited health resources and very little awareness of hemophilia among its people.

Objectives: This research study is designed to identify the prevalence of the disease and to report the types of haemophilia common in Pakistan in order to propose suitable treatments for the prevention and cure of the disease.

Methodology: A survey questionnaire was designed and executed by the group members. Data was collected from registered Haemophilia Centers in Pakistan. Number of reported cases based on types of haemophilia, age groups, and gender were identified separately.

Results: It was evaluated that Pakistan continues to have a growing number of hemophilia cases at an alarming rate. The research study also showed how there is a lack of affordable and proper health care in the country, due to which several cases go unreported and untreated.

Conclusion: For the containment of this bleeding disorder, time for taking proper action is passing. Proper health care systems should be set up which are accessible to the majority of the population. Awareness programs should be designed and people should be encouraged for regular laboratory tests to prevent late diagnosis.

\begin{tabular}{lcl} 
Keywords & *Address of Correspondence & Article info. \\
Haemophilia, Bleeding Disorder, Age, & kiranfatima14@gmail.com & Received: February 17, 2020 \\
Gender, Health Care & & Accepted: August 31, 2020 \\
\hline
\end{tabular}

Cite this article: Fatima K, Irfan R, Azmat L. Haemophilia: Its Types and Prevalence in Pakistan.

RADS J Biol Res Appl Sci. 2020; 11(2):120-126.

This is an Open Access article distributed under the terms of the Creative Commons Attribution License (http://creativecommons.org/licenses/by/4.0), which permits unrestricted use, distribution, and reproduction in any medium, provided the original work is properly cited.

\section{INTRODUCTION}

Haemophilia is a sex-linked recessive genetic disorder, associated with severe bleeding even as a consequence of minor injuries, due to the blood's inability to clot. This disease is associated with the absence of coagulation factor VIII ${ }^{1}$. found only on the X chromosome.

Fortunately, Hemophilia is not contagious and is more prevalent in males as compared to female counterparts. The disease results in bleeding that last longer than normal which is commonly internal and can end up in consequent swelling and pain if not ceased instantly the following treatment. Several episodes of bleeding in muscles or even joints can result due to the clotting factors being absent. This may be spontaneous, or lacking any specific cause, or may occur as a result of an injury. Injection and infusion into a vein is the mode of treatment for clotting the blood normally. If the condition prolongs in muscles or joints over a period of time, it may result in arthritis or even joint damage, resulting in the need for surgery coupled with chronic pain².

Majority of the cases occur due to inheritance from a parent however, one-third of the cases occur in those families who lack a prior history or a record of this 
disorder. The haemophilia genes are located on the $X$ chromosome. Males usually have one $X$ and one $Y$ chromosome (XY) while females have two $X$ chromosomes $(X X)$. Males inherit the $X$ chromosome from their mothers and the $Y$ chromosome from their fathers. Females inherit one $X$ chromosome from each parent. $A$ child inherits the gene for hemophilia is passed down from parents over generations. Daughters may acquire $X$ gene from their mothers and hemophilic fathers however, a son may only receive $X$ gene from his mother who carries the genes for the same. Sons, due to the presence of only one copy of $\mathrm{X}$ chromosome will be haemophilic in case they have the gene while the daughters may be the carriers of the disease but would not be affected, however they may experience a few bleeding problems ${ }^{3}$.

Previously, most patients suffering from haemophilia in the 1950s and the early 1960s lost their lives battling the disease in childhood or early adulthood. People of that time used lime, gelatin and snake venom etc. to treat haemophilic patients since the treatment procedures involved the utilization of fresh plasma or whole blood. Inadequate availability of Factors VIII and IX proteins in that period as compared to that required by the patients was not enough to cater for the problem of severe bleeding that they were afflicted with ${ }^{4}$. Enormous amounts of Factor VII being present in cryoprecipitate plasma as discovered by Judith Pool in 1964, paved the way to control the problem of severe bleeding by infusing Factor $\mathrm{VII}$ in rather minor quantities ${ }^{5}$. The magnified accessibility of lyophilized concentrates of coagulation factors in plasma, paved the way to the disorder's modern management, escalating in the 1970s, coupled with the rampant ratification of home replacement therapy which consequently resulted in the management of musculoskeletal damage and haemorrhages in patients being treated inadequately. The deterrence of bleeding in addition to bringing down the impact of arthropathy was achieved through prophylaxis originating in Sweden and then spreading across the globe ${ }^{6}$.

Currently, a predominant complication surrounding the establishment of Factor VII and IX alloantibodies imparting an inhibitory effect on them has become a demanding and formidable complication of the therapy. These inhibitors diminish the efficacy of the replacement therapies in addition to elevating the risks of mortality or morbidity in haemophiliacs and tapering them to retrieve and gain standard care ${ }^{7}$. An unprecedented advancement in treating the disorder in inhibitor patients is the instigation of Activated Prothrombin Complex Concentrates (APCC), Factor 8 inhibitor Bypassing Activity (FEIBA) and recombinant factor VII (rFVlla) which has been validated to have positive outcomes in boosting their condition $^{8}$. A decade long debate to determine the superior one among the above-mentioned products has been associated with the widespread potency and security of rFVIla and FEIBA being closely related, and that of the former being 10 to $15 \%$ higher as compared to APCC. The results of a study based on a Bayesian metaregression model conducted to determine the rate of controlling 2000 joint bleeds at therapy intervals of 12, 24 and, 36hrs were observed for rFVIla as $66,88,95 \%$ and APCC as $39,62,76 \%{ }^{9}$. However, both APCC and rFVIla ended up inducing results with indistinguishable hemostatic effects at the same efficacy without elevating thromboembolic risks. This can be concluded as a result of a contrasting study leading to the notion of both of the above-mentioned products being acceptable and extremely effective when it comes to treating the problem of severe bleeding in inhibitor patients ${ }^{10}$.

The efficacy and safety of the formerly disclosed developments have been put to use in the countries of west exclusively for the treatment of hemophiliacs over the preceding two decades. The future prospect thus lies in widening the disposability of this remedy ${ }^{11}$. The developing countries and the emergent nations like India and China, classified with unsatisfactory care for hemophiliacs and running towards accomplishing technological advancements and adequate expertise, can be more suitable for advancing further in gene transfer and processing recombinant factors assisting DNA technology in contrast to a program established on plasma fractionation ${ }^{12}$. On the contrary, countries of East Europe or Southern America, striving to improve the standards and conditions of haemophiliacs are in need of adequate supply of these factors attained from the plasma at a commercial scale due to the unaffordability of these factors which are of skyrocketing costs ${ }^{13}$.

The future prospective whilst, focused more at aiding the programs aimed for haemophilia care in developing countries also encompasses some objectives and 
schemes for the developed ones. The first and foremost amongst these, of critical importance, is the conservation and perpetuation of the system governing the care for haemophilia, which can suffer at the cost of the current commercial dilemma or catastrophe given that the amount put in from the budget in its entirety for the same purposes comprises only a minute proportion ${ }^{14,15}$. It is of pivotal importance that the therapy of factor replacement must be assisted in third world countries like those in Africa by the developed nations due to a blur future with regards to the availability of $R$ factors in these countries ${ }^{16,17}$.

\section{MATERIAL AND METHODS}

\section{Executing a Survey}

For the collection of new haemophilic cases data reported in the year 2017 was collected. We had also designed and executed a questionnaire (Appendix A). This questionnaire was sent to various registered haemophilia organizations around Pakistan to receive data from different cities.

The survey was divided into three main parts. The first part was to collect information about the haemophilia organizations filling out the questionnaire. The questions such as organization name, city, country, contact information and the name of the representative filling out the form were included. We also asked the respondent to write down what was their source for the numbers the second part, the respondent was asked to give numbers provided, how often their database was updated and who updated their database (doctors, nurses, clinics etc.) In terms of positive cases of haemophillia patients on the base of types of haemophilia, age groups of people and gender. The final part of the questionnaire asked for information regarding haemophilia treatment centers present in the country. We describe a center of treatment for haemophilia as a medical center dispensing basic diagnosis and treatment associated with inherited bleeding disorders.

\section{Collecting Data}

The data received from the questionnaires was then compiled on a single forum. They were sorted based on the answers received and on categories of questions. Those results that did not have any validation from a recognized organization were not included as part of this research study.

\section{RESULTS}

The data from section $A$ of the questionnaire was used to validate the rest of the information provided in the survey. Information regarding the centers that took part in our survey, based on the cities are located in, is compiled in Table 1. Moreover, the data collected based on age groups is sorted in Table 2.

Table 1. Organization Names and Location.

\begin{tabular}{cll}
\hline S. No. & Cities Covered & Organization Name \\
\hline 01 & Lahore & $\begin{array}{l}\text { Lahore Hemophilia Patients Welfare Society } \\
\text { Children Hospital and Institute of Child Health }\end{array}$ \\
& & Aga Khan University Hospital \\
02 & Karachi & Liaquat National Hospital \\
& & Husaini Blood Bank \\
& Rawalpindi & Bismillah Taqee Hospital- BTH \\
\hline 03 & Quetta & Hemophilia Patents Welfare Society- Center \\
04 & Samad Medical Centre \\
\hline
\end{tabular}


Table 2. Number of Patients Based on Age.

\begin{tabular}{ccc}
\hline S. No. & Age Group & Number of Cases Reported \\
\hline A & Haemophilia A & 1,464 \\
\hline 1 & $0-4$ & $6 \%$ \\
\hline 2 & $5-13$ & $23 \%$ \\
\hline 3 & $14-18$ & $13 \%$ \\
\hline 4 & $19-44$ & $33 \%$ \\
\hline 5 & $>45$ & $3 \%$ \\
\hline 6 & Age not known & $21 \%$ \\
\hline B & Haemophilia B & 279 \\
\hline 1 & $0-4$ & $6 \%$ \\
\hline 2 & $5-13$ & $21 \%$ \\
\hline 3 & $14-18$ & $14 \%$ \\
\hline 4 & $19-44$ & $32 \%$ \\
\hline 5 & $>45$ & $3 \%$ \\
\hline 6 & Age not known & $25 \%$ \\
\hline
\end{tabular}

From the data assorted in Table 2, we can infer that the total number of haemophilia cases reported in Pakistan is approximately 1743 , where the number of haemophilia $A$ patient (i.e. 1464) far exceeds the haemophilia B patients (i.e. 279). The percentage distribution of both types of haemophilia showed that their prevalence among the children belonging to the age group of 0-4 years was only $6 \%$, while 5-3-years old also showed similar patterns since $23 \%$ of the haemophilia $A$ belonged to that group and $21 \%$ of haemophilia $B$ belonged to that category. Comparatively, 14-18 years comprised a similar percentage of haemophilia $A$ and haemophilia $B$ patients with the former being $13 \%$ and the latter being $14 \%$, while $33 \%$ and $32 \%$ of the patients of haemophilia $A$ and $B$, respectively, lie in the category of $19-44$ years. While only $3 \%$ of the haemophilia, as well as haemophilia B patients, were above the age of 45 . Thus, one can infer that the percentage prevalence according to the age groups is almost similar in both the cases although the total number of cases of haemophilia B is greatly outnumbered by haemophilia A.

Figure $1 \& 2$ represent the age distribution of haemophilia $A$ and haemophilia B patients graphically. These signify that most of the haemophilic patients belong to the category of patients falling in the age group of 19-44 years. The least common age group among the haemophiliacs is $>45$. The charts also signify that a large proportion of haemophiliacs could not be categorized into the age groups since their ages were unknown. Their percentage can be equated to 21 and 25 , respectively, for haemophilia $A$ and haemophilia $B$.

Figure 3 represents the general distribution of the prevalence of haemophilia $A$ and haemophilia $B$ in Pakistan graphically with the number of haemophilia $A$ patient far exceeding those of haemophilia $B$. The results based on the gender prevalence of haemophilia is represented in figure 4 in the form of a pie chart which suggests a clear picture that the prevalence among females is greatly outnumbered by males.

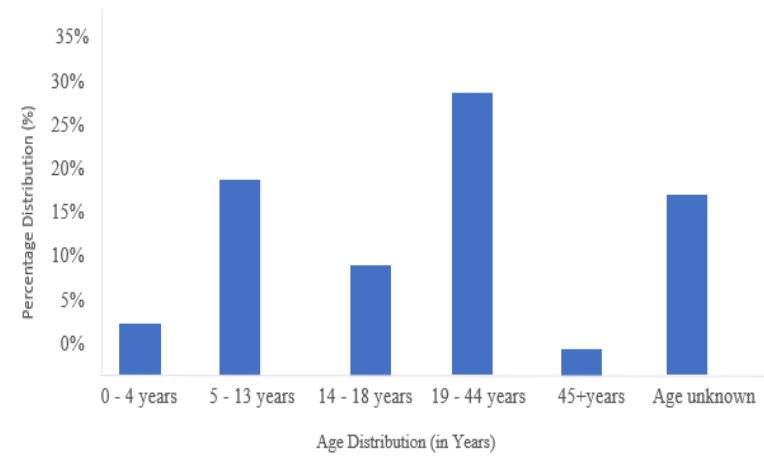

Figure 1. Age distribution of haemophilia A. 


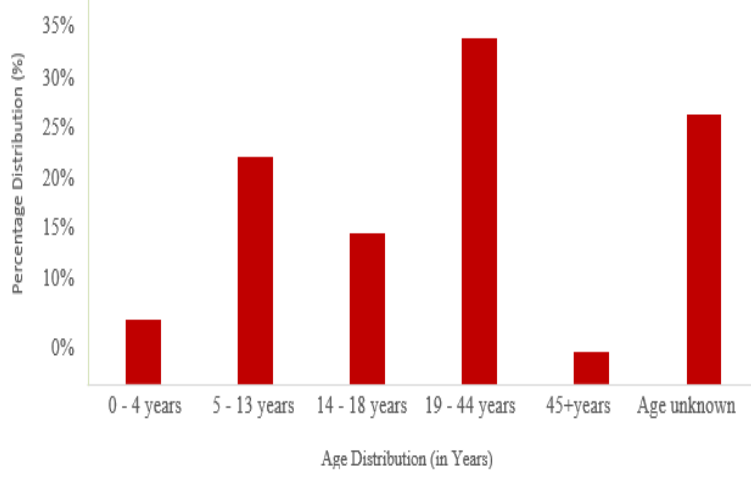

Figure 2. Age distribution of haemophilia B.

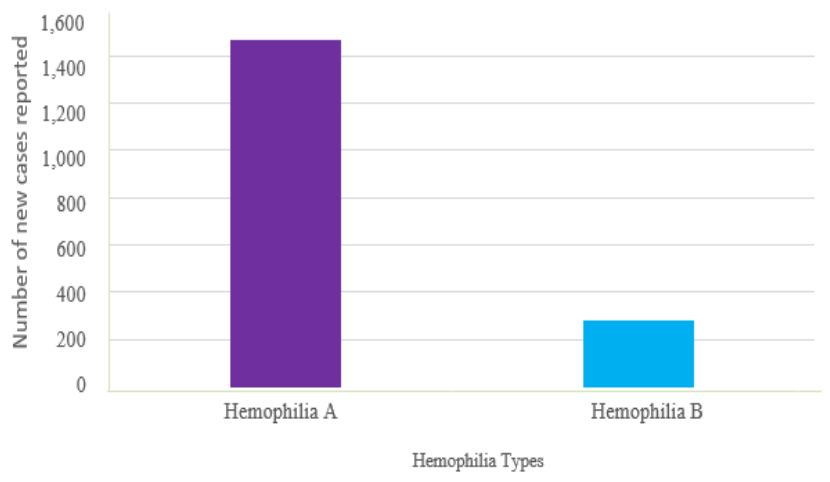

Figure 3. Types of haemophilia on the basis of patient's number.

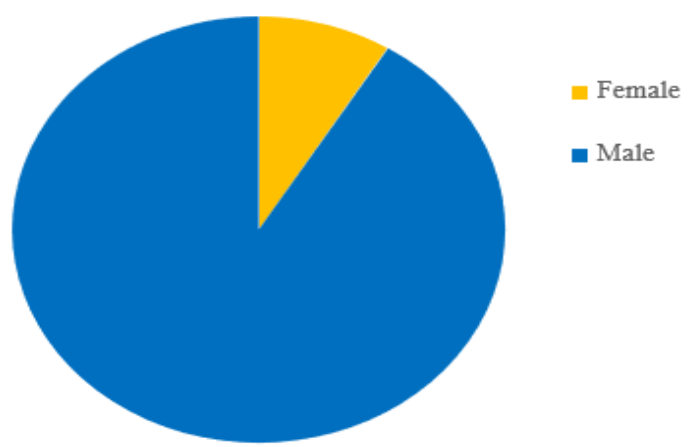

Figure 4. Distribution of haemophilia on the basis of gender.

\section{DISCUSSION}

From the results collected, we can see that the total number of cases reported annually in the year 2017 were 1,743 (Reported cases in Pakistan, 2017). Although the data represents that, the number of cases is lower than the cases reported in the previous years, it still remains big enough to attain serious attention.
Majority of the reported cases were of haemophilia type A. They were seen in patients of all age groups and both genders. However, in light of the aforementioned data, they were mostly common among people from ages 19 to 44 years (33\%) followed by age group of 5 to 3 years $(23 \%)$. A comparatively low percentage of people belonging to age groups $0-4$ years and $14-18$ years were positive for the disease with $6 \%$ and $13 \%$ positive cases, respectively. The least proportion of the diseased patients belonged to age group $>45$ years which was only $3 \%$. The age associated data was unknown for $21 \%$ of the recorded patients.

Haemophilia type B too has a significant number of cases. They were also found in patients of all age groups and both genders. Haemophilia type B was also found to be more common among ages 19 to 44 comprising a significant $32 \%$ of the reported cases. Second to this was that of the age group 5-13 years comprising $21 \%$. Likewise, $14 \%$ of the reported cases belonged to age group $14-18$ and only $6 \%$ of the $0-4$ years were positive for the disease. The least was of the $>45$ aged patients comprising only $3 \%$. However, these result could be due to late diagnosis of the inherited disease and limited resources available to the majority of the population in Pakistan.

Since, haemophilia is an X-linked recessive disease, it is more common in males than females. As evident from the aforementioned data, around $91 \%$ of the cases reported are males while the remaining $9 \%$ makes up the female population. A father affected with haemophilia will pass its gene to his daughter, who may either get affected or at least will be a carrier for the disease. If an affected mother passes the gene to her son, he will also get the disease.

\section{CONCLUSION}

One alarming fact is that Pakistan being a developing country has very few health resources compared to its large population, rendering a small proportion of haemophilic families to suffer at the cost of inadequate cryoprecipitate or frozen plasma treatment compared to the masses who are unable to withstand an excessive cost of therapy for the replacement of Factor VII. Due to this improper treatment, the disease progresses and develops into a chronic one accompanied by fatal complications as well as disabilities. 
Several cases go unreported which contribute to being left untreated and then being passed down from one generation to the next. Firstly, the higher number of people competing for a few limited resources. Secondly treatment centers are not properly supervised and they carryout unethical procedures e.g. same needles may be used to inject medicines which result in HIV and STDs being passed to others.

The solution to all these problems is early diagnosis and proper standardized treatments for eradication or at least limiting the prevalence of haemophilia. Awareness should be created among people, in both urban and rural areas, and more people should be encouraged to take laboratory diagnostics done regularly.

\section{CONFLICTS OF INTEREST}

None.

\section{FUNDING SOURCE}

None.

\section{ACKNOWLEDGEMENTS}

We are extremely thankful to all the organizations for their support in this project and we are also thankful to Dr. Saiqa Tabassum for helping in data analysis.

\section{LIST OF ABBREVIATIONS}

APCC

Activated Prothrombin Complex Concentrates

FEIBA Factor 8 inhibitor Bypassing Activity

rFVII Recombinant Factor VII

STDs Sexually Transmitted Diseases

\section{REFERENCES}

1. Nichols WL, Hultin MB, James $A H$, Manco-Johnson MJ, Montgomery RR, Ortel TL, et al. von Willebrand disease (VWD): Evidence-based diagnosis and management guidelines, The National Heart, Lung, and Blood Institute (NHLBI) Expert Panel report (USA) 1. Haemophilia. 2008 Mar; 14(2):171-232.

2. Persson A, Ellard J, Brown G, Newman C, Prestage G. You, Me \& HIV: The serodiscordant couples study. Sydney: Centre for Social Research in Health, UNSW Australia. 2016; 2-48.

3. Skinner MW. Haemophilia: Provision of factors and novel therapies: World Federation of Hemophilia goals and achievements. British J Haemat. 2011; 154(6):704-14.

4. Poon MC, Luke KH. Haemophilia care in China: Achievements of a decade of World Federation of Hemophilia treatment Centre twinning activities. Haemophilia. 2008; 14(5):879-88.

5. Evatt B. World federation of hemophilia guide to developing a national patient registry. Montreal: World Federation of Hemophilia. 2005; 1-40.

6. Franchini M, Mannucci PM. Past, present and future of hemophilia: A narrative review. Orphanet J Rare Dis. 2012; 7(1):1-8.

7. Astermark J, Santagostino E, Keith Hoots W. Clinical issues in inhibitors. Haemophilia. 2010; 16:54-60.

8. Astermark J, Donfield SM, DiMichele DM, Gringeri A, Gilbert SA, Waters J, et al. A randomized comparison of bypassing agents in hemophilia complicated by an inhibitor: The FEIBA NovoSeven Comparative (FENOC) Study. Blood. 2007; 109(2):546-51.

9. Treur MJ, McCracken F, Heeg B, Joshi AV, Botteman $M F$, De Charro $F$, et al. Efficacy of recombinant activated factor VII vs. activated prothrombin complex concentrate for patients suffering from haemophilia complicated with inhibitors: A Bayesian meta-regression. Haemophilia. 2009; 15(2):420-36.

10. Iorio A, Matino D, D'Amico R, Makris M. Recombinant Factor VIla concentrate versus plasma derived concentrates for the treatment of acute bleeding episodes in people with haemophilia and inhibitors. Cochrane Database Syst Rev. 2010; (8):1-15.

11. Skinner MW. WFH: Closing the global gap-achieving optimal care. Haemophilia. 2012; 18:1-2.

12. Loo M. Integrative medicine for children. Elsevier Health Sci. 2008; 5(5):277-89.

13. Bauer KA. Current challenges in the management of hemophilia. Am J Manag Care. 2015; 21(6):S112-22.

14. O'Mahony B, Black $C$. Expanding hemophilia care in developing countries. In Seminars in thrombosis and hemostasis. 2005; 31(05):561-568.

15. Ghosh K. Management of haemophilia in developing countries: Challenges and options. Indian J Hematol Blood Transf. 2016; 32(3):347-55.

16. Saenko EL, Ananyeva NM, Shima M, Hauser CA, Pipe SW. The future of recombinant coagulation factors. J Thromb Haemost. 2003; 1(5):922-30.

17. Saenko EL, Pipe SW. Strategies towards a longer acting factor VIII. Haemophilia. 2006; 12:42-51. 
APPENDIX - A

SURVEY ON HAEMOPHILIA PREVALENCE 2018

\section{A. National Hemophilia Organization}

\begin{tabular}{|l|l|}
\hline Organization name & \\
\hline City & \\
\hline Country & \\
\hline Phone & \\
\hline E-mail & \\
\hline This form completed by: & \\
\hline
\end{tabular}

We would like to know how you collect the data you are providing for this survey.

\begin{tabular}{|l|l|}
\hline $\begin{array}{l}\text { What is the source of the numbers provided for this } \\
\text { survey? }\end{array}$ & $\begin{array}{l}\text { Check one } \\
\text { Hemophilia Society } \\
\text { Health Ministry registry } \\
\text { Other(please describe): }\end{array}$ \\
\hline How often is your database updated? & Ongoing update \\
& Yearly update \\
& Other(please describe): \\
\hline Who updates the database? & Doctors \\
& Patient organization \\
& Hospitals or clinics \\
& Other(please describe): \\
\hline
\end{tabular}

B. Identified Patients (Please DO NOT estimate or guess)

\begin{tabular}{|c|c|c|c|c|c|}
\hline \multirow{2}{*}{\multicolumn{4}{|c|}{ Total number of identified people with hemophilia A or B, or type unknown }} & Number & Not known \\
\hline & & & & & $\square$ \\
\hline \multicolumn{4}{|c|}{ Do you consider these numbers to be accurate? } & Yes & Not sure \\
\hline Age group & $\begin{array}{l}\text { Numbe } \\
\text { hemop }\end{array}$ & & & \multicolumn{2}{|c|}{$\begin{array}{c}\text { Number with hemophilia type } \\
\text { unknown }\end{array}$} \\
\hline \multicolumn{6}{|l|}{$0-4$ yearsold } \\
\hline \multicolumn{6}{|l|}{ 5-13yearsold } \\
\hline \multicolumn{6}{|l|}{ 14-18yearsold } \\
\hline \multicolumn{6}{|l|}{ 19-44yearsold } \\
\hline \multicolumn{6}{|l|}{45 years or older } \\
\hline \multicolumn{6}{|l|}{ Unknown age } \\
\hline \multicolumn{6}{|l|}{ No age data } \\
\hline Diagnosis & Total & Male & Female & Gender unknown & No data \\
\hline \multicolumn{6}{|l|}{ Haemophilia A } \\
\hline \multicolumn{6}{|l|}{ Haemophilia B } \\
\hline \multicolumn{6}{|l|}{ Type unknown } \\
\hline Do you consid & numbers & & & & ot sure \\
\hline
\end{tabular}

\section{Hemophilia Treatment Centers}

How many haemophilia treatment centers are there in total in your country?

How many of these centers have direct access to a hemophilia doctor, nurse,

physiotherapist, social worker, and special coagulation laboratory? 